\title{
FACTORS AFFECTING THE SUCCESS OF HOSPITAL MANAGEMENT INFORMATION SYSTEM: A SYSTEMATIC REVIEW
}

\author{
Andini Tri Wijayati, Anhari Achadi
}

\author{
Masters Program in Public Health, Universitas Indonesia
}

\begin{abstract}
Background: Hospital Management Information System (HMIS) has an important role in increasing the effectiveness and efficiency of hospital services. However, the implementation of information systems is complex and requires a large investment. To prevent failure, it is important to know the success factors in the implementation of HMIS. This study aimed to review systematically the factors affecting the success of hospital management information system.

Subjects and Method: This was systematic review following PRISMA model. The review was conducted by searching published articles in English and Indonesian from 2014 to 2019 from electronic databases including EBSCOhost, ProQuest, ScienceDirect, Scopus, and Google Scholar. The keywords were hospital management information system, hospital information system, implementation, and success factor. After review process, 8 articles were included in this review.

Results: Three articles stated that human and technology were influential factors in the implementation of HMIS. An article stated financial and an article stated functional as influential factor in the implementation of HMIS. Other influential factors included organizational and environmental factors. Conclusion: Human and technological are significant factors that influence the success of HMIS.
\end{abstract}

Keywords: hospital management information system, hospital information system, implementation, success factor.

Correspondence:

Andini Tri Wijayati. Masters Program in Public Health, Universitas Indonesia, Depok, West Java. Email: andini.triwi@gmail.com Mobile: 081295910529.

\section{BACKGROUND}

Information and Communication Technology (ICT) has experienced rapid development and has touched various fields, including health. The hospital as an institution that provides health services to the community processes a lot of data and information during the service process. To ensure that data can be processed properly so as to produce useful, accurate, and accurate information that can be accessed by all parties involved in the provision of services, ICT infrastructure assistance is needed and is known as hospital information systems.

Information systems can be defined as a combination of hardware, software, infrastruc- ture, and trained personnel to facilitate planing, control, coordination, and decision making, and develop mechanisms to translate data into meaningful information to achieve the specific goals of an organization (Tabibi et al., 2018).

Hospital Management Information System (HMIS) is a computer-based medical information system for patient care and hospital management. HMIS computerizes financial, administrative and patient care activities in hospitals, produces management reports and operational statistics, and offers a powerful query module. The terms hospital management and information systems, patient information

The $6^{\text {th }}$ International Conference on Public Health Best Western Premier Hotel, Solo, Indonesia, October 23-24, 2019 | 246 https://doi.org/10.26911/the6thicph-FP.04.04 
systems, medical information systems, health information systems, clinical information systems, and hospital information systems have slightly different meanings but are often used interchangeably (Bansal, 2003).

Hospitals by adopting Information Technology (IT) applications such as HMIS will benefit greatly, from the medical system to the administrative system (Esfahani et al., 2018). Several studies have shown that health information systems improve access, improve the quality and efficiency of medical care and services, increase the accuracy of information and activities, reduce the work time, and increase the speed of work (Tabibi et al., 2018).

While it is important that this system is implemented as part of a holistic health information system, there are challenges in sustainable use and overall success (Ojo and Popoola, 2015). Several studies have shown that a large number of large-scale information system projects are faced with failure for various reasons (Farzandipur, Jeddi and Azimi, 2016). A study by Fowler shows that only $28 \%$ of information systems have successful performance (Nilashi et al., 2016). In addition to incurring huge costs on the organization, this system failure has a negative impact on staff and patient care (Farzandipour et al., 2017). To get the expected benefits for health care, it is very important that this system is successfully implemented and used continuously from time to time (Ojo and Popoola, 2015).

Therefore, this study aims to explore the factors that affect the successful implementation of HMIS in hospitals. In addition to reduce the possibility of failures and their effects, the exploration of these factors will help in developing and proposing a framework for understanding the design, development and implementation of a successful HMIS.

\section{SUBJECTS AND METHOD}

\section{a. Study Design}

This systematic review study referred to the guidelines for Preferred Reporting Items for Systematic Reviews and Meta-Analyzes (PRISMA). Articles were obtained from electronic database searches, namely EBSCOhost, ProQuest, ScienceDirect, and Scopus, as well as the Google Scholar search engine. The keywords used were hospital management information system, hospital information system, implementation, and success factors.

\section{b. Inclusion and Exclusion Criteria}

Inclusion criteria were articles in English and Indonesian, published between 2014 and 2019. Sources of data were scientific journals, conference articles, and proceedings. Exclusion criteria were articles outside of Indonesian and English, not open access articles, only abstracts, articles published under 2014. 

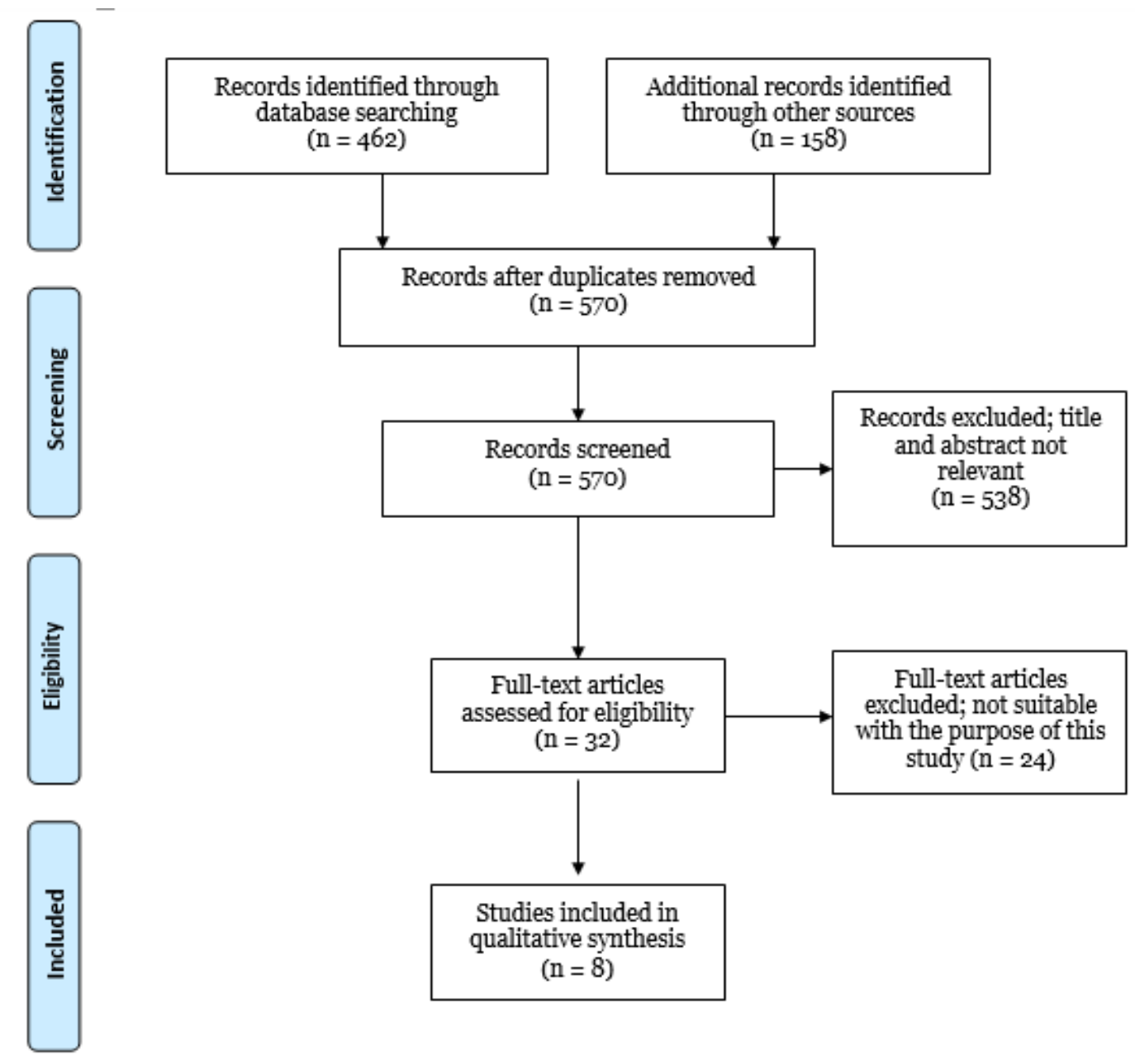

Figure 1. PRISMA Flow Diagram

\section{RESULT}

\section{Quantity of systematic review}

In the initial search using keywords, inclusion criteria, and exclusions found 620 articles. Then after checking for duplication, 570 articles were obtained, 32 articles were screened based on abstracts. Then after being screened based on full paper and assessed for eligibility, 8 documents were found to be eligible for this study.

\section{Reported factors affecting the success of HMIS implementation}

Tabel 1. Results of the Study Reviewed
From a study conducted on 8 studies, each of the 3 studies stated that human factors and technological factors were the most influential factors in the successful implementation of HMIS. In addition, 1 study stated financial factors and 1 study stated functional factors as the most influential factor in the successful implementation of HMIS. In addition to these key factors, there were other factors that also influence the successful implementation of HMIS, namely organizational and environmental factors. 
Table 1. Articles reviewed in this study

\begin{tabular}{cll}
\hline Author (Year) & \multicolumn{1}{c}{ Place } & \multicolumn{1}{c}{ Title } \\
\hline Ismail et al.(2015) & Malaysia & Adoption of Hospital \\
& & Information System \\
& (HIS) in Malaysian \\
& Public \\
& Hospitals
\end{tabular}

Esfahani et al. (2018)

Iran

Lian (2014)

Taiwan

Nilashi et al. (2016)
Iran
An evaluation model for the implementation of hospital information system in public hospitals using multicriteria-decision-making (MCDM) approaches

An exploratory study to understand the critical factors affecting the decision to adopt cloud computing in Taiwan hospital

Determining the importance of Hospital Information System adoption factors using Fuzzy Analytic Network Process (ANP)

\section{Result}

The human factor is the most influential factor in the adoption of hospital information systems. Then followed by the organization in second, environment in third, and technology in fourth.

Technology is the most important dimension in the adoption of hospital information systems. In second place is human and in third is organization.

Among the four different dimensions, the most important factor is technology, followed by humans, organizations, and the last is the environment. Among the four different dimensions, the most important factor affecting the decision to adopt IT innovation is technology, followed by the environment, the organization, and the last is humans.

\section{Conclusion}

This study stated that the human factor has the highest effect in the adoption of Malaysia's General Hospital information system. This might imply the importance of human skills, experience, expertise, satisfaction and quality of information for the adoption of a successful hospital information system.

This study revealed that respondents of the study preferred the technological and human dimensions. Thus, the findings obtained in this study provide guidance for management in choosing the right way for the adoption of hospital information systems, preparing effective mitigation strategies, and contingency plans prior to implementation and helping hospitals to understand their strategic objectives in increasing efficiency.

This study identifies key factors that affect hospital decisions to adopt cloud computing technology. Hospitals can refer to the findings of this study to make better decisions.

Four main contexts, namely technology, environment, organization, and human have a significant effect on the overall adoption decision of the hospital information system.

The $6^{\text {th }}$ International Conference on Public Health Best Western Premier Hotel, Solo, Indonesia, October 23-24, $2019 \mid 249$

https://doi.org/10.26911/the6thicph-FP.04.04 
Some Correlates of Electronic Health

Information

Management System

Success in Nigerian

Teaching Hospitals

Sheykhotayefeh et al.

(2017)

Iran

Hospital Information

Systems

Implementation: An

Evaluation of Critical

Success Factors in

Northeast of Iran

Farzandipur et al. (2016)

Iran

Factors Affecting

Successful

Implementation of

Hospital Information

Systems

Malaysia

Sulaiman and
Financial factors are significantly related to the success of the Electronic

Health Information

Management System

(EHIMS) in Nigerian

teaching hospitals. Then

followed by organizational

factors, social factors,

political factors, and

technical factors.

Factors that influence the

successful implementation of hospital information systems in order of priority:

functional, project

management, human,

technical, and management.

Human factors have the

biggest effect on the

successful implementation of

hospital information systems

and then followed by

technological factors,

organizational factors, and

managerial factors.

Assimilating Healthcare Topics related to human

Wickramasinghe
Information Systems in a Malaysian Hospital esources are the highest

issues discussed at Alpha

Hospital.
This study explores the factors that contribute to the success of EHIMS in Nigerian teaching

hospitals. The health sector is well informed and therefore there is a need to invest in an effective and efficient EHIMS.

The successful implementation of a hospital information system is affected by many factors. Among these, the most important are functional factors, project management factors, human

factors, technical, and management. In addition to the factors listed, several factors such as cultural, ethical and behavioral factors can be effective in some specific areas and sections.

Human factors in general have an important role in the adoption and successful implementation of hospital information systems. Then followed by technological factors, organizational factors and madnagerial factors.

The findings from the analysis of each theme identify elements that can affect the success of the assimilation of certain hospital information systems.

The $6^{\text {th }}$ International Conference on Public Health Best Western Premier Hotel, Solo, Indonesia, October 23-24, $2019 \mid 250$ 


\section{DISCUSSION}

1. Human

Human factors that affect the success of hospital information systems include general knowledge and skills in computer use, ease of using hospital information systems and ease of learning to use them. Anderson, in a 2007 study in eHealth, suggested that more than half the population had mentioned the lack of knowledge about the use of computers and information technology as a barrier to using Information Technology (IT). The ease of learning how to use HMIS will make users familiar with the system and in addition to saving time and money, will lead to the successful adoption and implementation of the system by end users (Farzandipur, Jeddi and Azimi, 2016).

In addition, human training is one of the most important factors for avoiding hospital information system failures. In this case, ongoing training is very important for successful implementation (Sheykhotayefeh et al., 2016).

User participation in the implementation process is another factor that can affect the successful implementation of HMIS. End users must have significant involvement in IT initiatives and developers must consider personnel feedback before, between and during system design and design. (Sheykhotayefeh et al., 2016)

2. Technology

The technological dimension represents the technical problems involved in the adoption of computing technology. Some things that are included in the technology dimension are security, privacy, software, and hardware compatibility.

The issue of security is the most important issue in the context of the distribution environment including in the cloud computing environment (Subashini \& Kavitha, 2011; Zissis \& Lekkas, 2012 in Lian, Yen and Wang, 2014).
This certainly applies to hospitals because health care data require a safer environment for storage and withdrawal. Ensuring data security and confidentiality of hospital information systems is very important. A lot of valuable data is stored in the system. Unsafe data can be misused and violated and can cause unpleasant events for patients. (Clifford, Blaya, Hall-Clifford, \& Fraser, 2008 in Sheykhotayefeh et al., 2016). Privacy issues are also an important concern in the health care industry (Barua, Liang, Lu, \& Shen, 2011 in Lian, Yen and Wang, 2014).

Technical factors in this study also include hardware and software compatibility. Properly designed software, infrastructure that supports system implementation, easy-to-use software, adequate hardware components, adequate technical support from the system provider, supporting communication network infrastructure, evaluation of software prior to implementation, and sufficient expertise to HMIS operation. (Ojo and Popoola, 2015)

\section{Finance}

Financial factors include the availability of funds for system maintenance, strong expectations of return on investment, cost-benefit analysis, and sufficient budget for sustainable operations. Implementing HMIS involves substantial capital investment and ongoing financial investment in operating and maintaining the system to sustain its success. The cost and lack of awareness of return on investment is usually the biggest obstacle to the successful implementation and adoption of HMIS. (Ojo and Popoola, 2015)

4. Functionality

Functionality is one of the most influential factors in the successful implementation of a hospital information system. A study shows that the system will not be achieved if there are unclear functions and poor user interface design (lack of clarity in functionality and poor

The $6^{\text {th }}$ International Conference on Public Health Best Western Premier Hotel, Solo, Indonesia, October 23-24, 2019 | 251 https://doi.org/10.26911/the6thicph-FP.04.04 
user-interface design) (Sheykhotayefeh et al., 2016).

5. Other Factors (Organizational and Environmental)

Organizational factors include top management's commitment to system success, support from various departments involved in system operations, management's rapid presence in system maintenance, well-defined system processes, consensus that is usually reached by various department heads regarding operating systems, top management leadership style , user motivation by management, planning and coordination for system success, and minimal disruption to normal workflows.

These results imply that factors such as leadership style and organizational commitment to the success of the electronic health information system will undoubtedly contribute to its success. In addition, the extent to which all stakeholders work together and are involved and the stability of the management structure is fundamental to the successful introduction of innovation. (Ojo and Popoola, 2015)

In addition high quality project management and detailed planning will ensure good implementation, institutionalization and user acceptance (Ismail et al., 2010 in Sheykhotayefeh et al., 2016).

The environmental dimensions in this study include government policy, industrial, social and political pressure. Political factors, such as changes in government, the desire to invest on the part of the government, government policies, tools for quality assurance, and flexible government bureaucracy, will affect the successful implementation of HMIS. The role of government is also very important in technology adoption and cannot be ignored. Government policies on tax and tariff subsidies, rules and regulations, restrictions, and incen- tives and support for technology play an important role in their acceptance and rejection. (Ojo and Popoola, 2015).

This study explores the factors that affect the successful implementation of HMIS. From the study, it was found that human factors and technology are the factors that have biggest influence in the successful implementation of HMIS. In addition to these two factors, financial, functional, organizational, and environmental factors also affecr the successful implementation of HMIS.

The implementation of HMIS requires a large investment. In addition, the adoption of this new platform can completely change the nature of the operation of information systems in hospitals and may have a significant impact on these hospitals. Therefore, caution, analysis, and careful preparation are required before adopting HMIS. By understanding the success factors of HMIS implementation, it is expected to increase the success rate of effective and efficient HMIS implementation.

\section{REFERENCES}

Bansal M (2003). Medical Informatics A Primer. New Delhi: Tata McGraw-Hill Publishing Company Limited.

Esfahani A A, Ahmadi H, Nilashi M, Alizadeh M, Bashiri A, Farajzadeh MA, Shahmoradi L, Rasouli HR, Hekmat M (2018). An Evaluation Model for the Implementation of Hospital Information System in Public Hospitals Using Multi-Criteria-DecisionMaking (MCDM) approaches. International Journal of Engineering and Technology(UAE), 7(1): 1-18. doi: 10.14419/ijet.v7i1.8404.

Farzandipour M, Meidani Z, Gilasi H, Dehghan R (2017). Evaluation of Key Capabilities for Hospital Information System: A Mile- 
stone for Meaningful Use of Information Technology. Annals of Tropical Medicine and Public Health, 10(6): 1587-1590. doi: 10.4103/ATMPH.ATMPH.

Farzandipur M, Jeddi FR, Azimi E (2016) 'Factors Affecting Successful Implementation of Hospital Information Systems', Acta Informatica Medica, 24(1), pp. 51-55. doi: 10.5455/aim.2016.24.51-55.

Lian JW, Yen DC, Wang YT (2014). An Exploratory Study to Understand the Critical Factors Affecting the Decision to Adopt Cloud Computing in Taiwan Hospital. International Journal of Information Management. Elsevier Ltd, 34(1): 28-36. doi: 10.1016/j.ijinfomgt.2013.09.004.

Nilashi M, Hossein A, Ali A, Ramin R, Othman bin I (2016). Determining the Importance of Hospital Information System Adoption Factors Using Fuzzy Analytic Network Process (ANP)', Technological Forecasting and Social Change. Elsevier B.V., 111: 244264. doi: 10.1016/j.techfore.2016.07.008. Ojo AI, Popoola SO (2015). Some Correlates of Electronic Health Information Management System Success in Nigerian Teaching Hospitals. Biomedical Informatics Insights, 7. doi: 10.4137/bii.s20229.

Sheykhotayefeh M, Safdari R, Ghazisaeedi M, Mohammadzadeh N, Khademi SH, Torabi V, Jebraeily M, et al, (2016). Hospital Information Systems Implementation: An Evaluation of Critical Success Factors in Northeast of Iran. Global Journal of Health Science, 9(2): 93. doi: 10.5539/gihs.v9n2p93.

Tabibi SJ, Ebrahimi P, Fardid M, Amiri MS (2018). Designing a Model of Hospital Information System Acceptance: Organizational Culture Approach. Medical Journal of the Islamic Republic of Iran, 32(1): 158-164. doi: 10.14196/MJIRI.32.28. 